\title{
TRANSPORT CALCULATIONS OF CHEMICALLY SPUTTERED CARBON NEAR A PLASMA DIVERTOR SURFACE
}

by

Jeffrey N. Brooks

\section{FUSION POWER PROGRAM}

Operated by

Argonne National Laboratory 9700 South Cass Avenue Argonne, Illinois 60439
The University of Chicago for the U.S. Department of Energy under Contract W-31-109-Eng-38 
Arenne Narronal Labuarory. with facilities in the states of illinos and Idaho, is

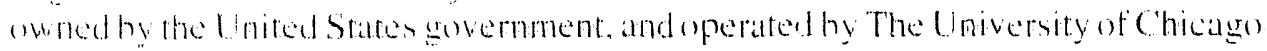
under the provingons of a contract with the Department of Energy.

\section{DISCLAIMER}

Thie report was prepared als an accoun of work sponsured hy an agency of the Inited St tres Government. Neither the United States Government nor

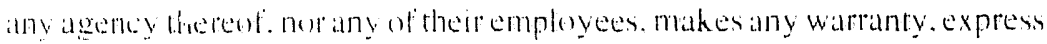
ar implied, or assume any legal tiability or responsibility for the accuracy. complefeness or ancfulness at any informations apparatus product or proche dixched. or represent that its use would not intringe privately owned righte. Reference herein on any specilic commercial product. process, or serves he rade name. tratemark. manufacturer. or orherwise, does not necenarily comstitute or imply its endorsement. recommendation. ar

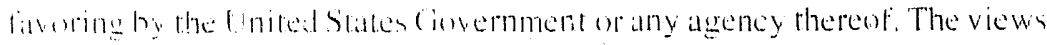

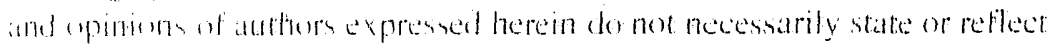
thene of the Inicel states (imernment or any agency thereot.

Reproduced from the heor avalathe copy.

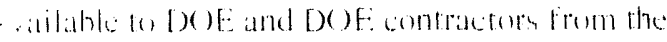

() flice of Sicientific and Technical Information

P. (1) Bu, 0 ?

().ak Rulec TN 37831

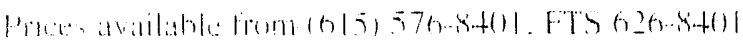

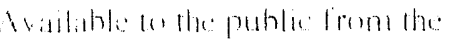

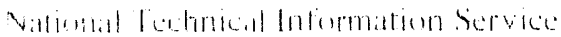

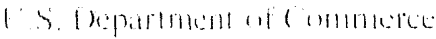

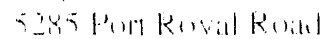

sproutich v 122101 
Distribution Category:

Plasma Fusion Systems UC-421

Magnetic Fusion Reactor Materials UC -423

ANL/FPP/TM-259

AML/FPP/TM - 259

DE92 009022

ARGONNE NATIONAL LABORATORY

9700 South Cass Avenue

Argonne, Illinois 60439-4801

\title{
TRANSPORT CALCULATIOUS OF CHEMICALLY SPUTTERED CARBON NEAR a PLASKa dIVERTOR SURFACE
}

\author{
by \\ Jeffrey N. Brooks \\ Fusion Power Program \\ Engineering Physics Division \\ January 1992 \\ Work supported by \\ Office of Fusion Energy \\ U.S. Department of Energy \\ Under Contract $W-31-109-E n g-38$
}


TABLE OF CONTENTS

Page

Abstract $\ldots \ldots \ldots \ldots \ldots \ldots \ldots \ldots \ldots \ldots \ldots \ldots \ldots \ldots \ldots \ldots \ldots \ldots \ldots \ldots \ldots \ldots \ldots \ldots \ldots \ldots$

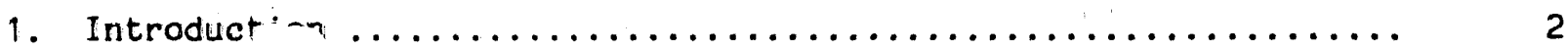

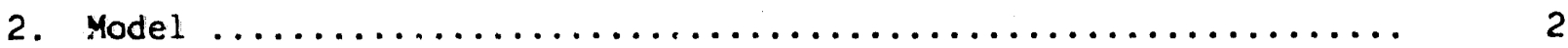

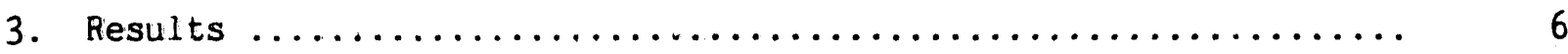

4. Conclusions .................................... 12

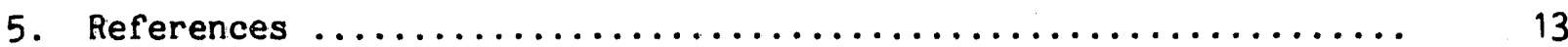

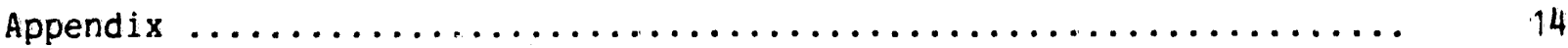




\section{LIST OF TABLES}

Page

Table 1 Carbon Chemical Sputtering Analysis - Summary of Redeposited Particle Parameters. For Plasma Parameters $\mathrm{N}_{\mathrm{e}_{\mathrm{o}}}=3 \times 10^{20} \mathrm{~m}^{-3}, \Psi=87^{\circ}, \mathrm{B}=5 \mathrm{~T}$, $f_{D}=0.25, e \phi_{O}=-3 k T_{e}$.

Table 2 Redeposited Particle Parameters as a Function

of Plasma Density. For $\mathrm{T}_{\mathrm{e}}=10 \mathrm{eV}, \Psi=87^{\circ}$, $B=5 T, f_{D}=0.25, e \phi_{0}=-3 k T e$.

\section{LIST OF FIGURES}

$\underline{\text { Page }}$

Figure 1 Model geometry. $\ldots \ldots \ldots \ldots \ldots \ldots \ldots \ldots \ldots \ldots \ldots$

Figure 2 Sample histories of chemically sputtered carbon. 7

Figure 3 Redeposited species nix, for reference plasma conditions. 


\section{TRANSPORT CALCULATIONS OF CHEMICALLY SPUTTERED}

CARBON NEAR A PLASMA DIVERTOR SURFACE

by

Jeffrey N. Brooks

\section{ABSTRACT}

The transport of chemically sputtered carbon near a tokamak divertor surface has been analyzed with the Monte Carlo code WBC. The code follows the motion of sputtered methane atoms and the resulting carbon and hydrocarbon derivatives. Ion transport due to the magnetic field, sheath electric field, and collisions with the plasma is computed. Redeposition fractions, impinging species type, charge state, and velocity have been analyzed. For plasma temperatures $\geq 10 \mathrm{eV}$, and for typical divertor plasma densities, local redeposition of chemically sputtered carbon approaches 100\%. Redeposition fractions are lower $(-80 \%)$ for lower temperatures and/or lower density. Physical sputtering of carbon due to redeposition of chemically sputtered material is low but a hydrocarbon reflection cascade due to redeposition may be high. 


\section{INTRODUCTION}

Sputtered particle transport in a tokamak is critically important to erosion and plasma contamination. Recent studies $(1-4)$ have examined the transport of physically sputtered carbon, beryllium, niobium, and tungsten, and radiation enhanced sublimated carbon, for fusion plasma divertor conditions. The transport of chemically sputtered carbon is a more complex process because of the large number of species and reactions involved. It is difficult, experimentally, to resolve the effects of chemical sputtering (5), and numerical studies can therefore be useful. A numerical study of methane transport, for small-tokamak limiter conditions(6), found a substantial penetration of carbon to the main plasma. He expect different results for a reactor type divertor plasma, and when the sheath field and magnetic field is taken into account. An approximate analysis ${ }^{(7)}$ of chemically sputtered carbon erosion/redeposition was performed for the ITER divertor design using the REDEP code. That study, which used a crude chemically sputtered carbon transport model, indeed predicted high local redeposition.

The purpose of the present study is to provide a more rigorous analysis of chemically sputtered carbon transport, at least for a trace impurity content plasma. To analyze this subject, the WBC Monte Carlo Code(1) was substantially upgraded to include the treatment of hydrocarbon neutrals and ions. The analysis uses the 34 reaction rates and processes compiled by Ehrhardt and Langer ${ }^{(8)}$. Due to an apparent lack of experimental data, an adhoc model developed by Ruzic ${ }^{(9)}$ was used for describing hydrocarbon reflection at the surface. The analysis was done primarily for typical plasma divertor conditions.

\section{MODEL}

The basic WBC model is described in Ref. [1]. The code computes the motion of sputtered particles in a fixed background D-T plasma. Fig. 1 shows the model geometry. The magnetic field lies in the $z-y$ plane and is uniform in the $x$-direction. For this analysis, the plasma is assumed uniform in the $x-y$ plane. The plasma sheath region is modeled with a dual exponential structure with a Debye region e-folding distance of $2 \lambda_{D}$, and a magnetic sheath region e-folding distance equal to the D-T ion gyroradius. The code computes 


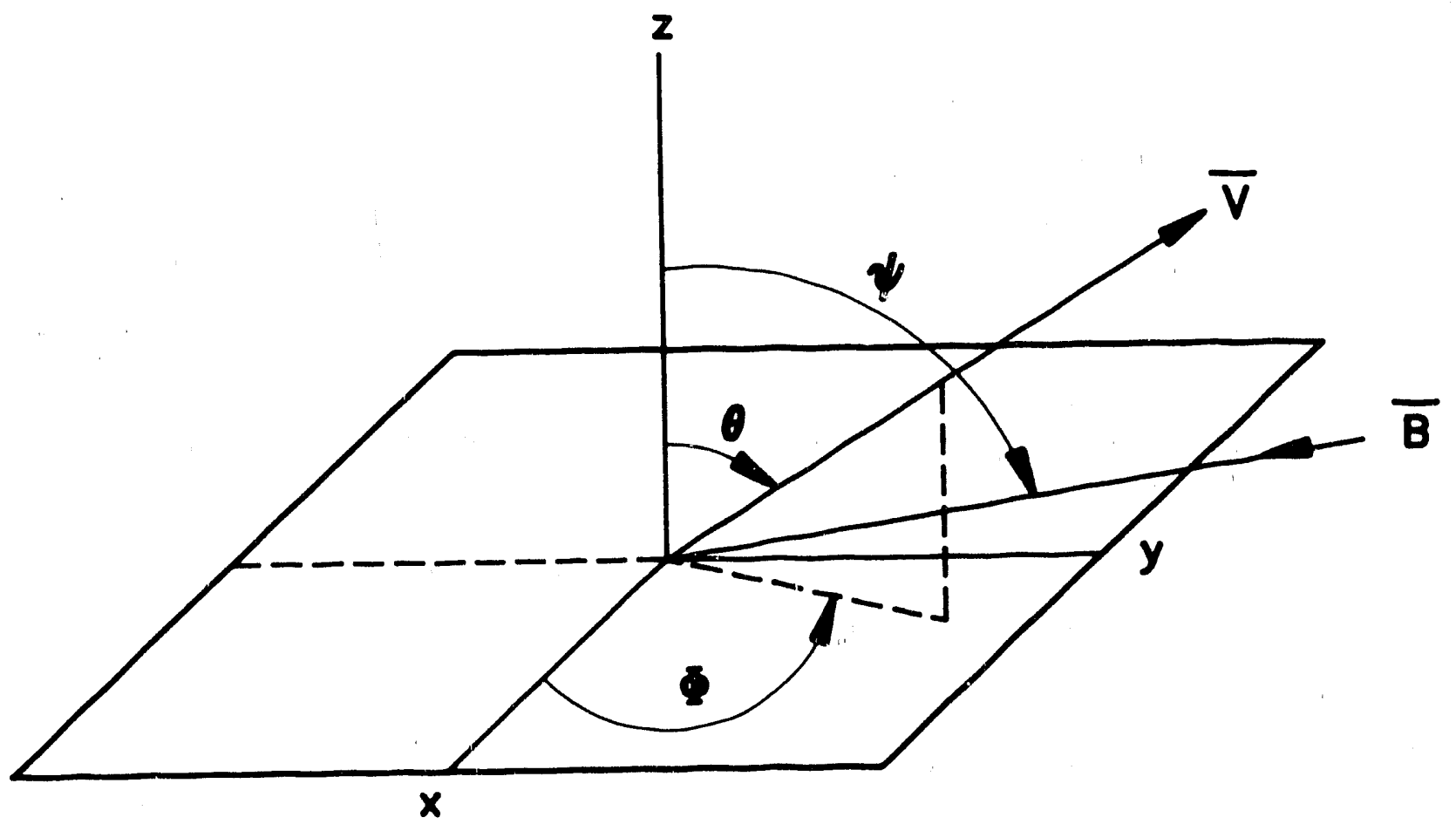

Figure 1. Model geometry.

the motion of the carbon and hydrocarbon neutrals and ions due to magnetic and electrical forces and charge changing and velocity changing collisions with the plasma.

To simulate hydrogen chemical sputtering of carbon, methane molecules are launched in the code with random velocities corresponding to a thermal energy distribution at $1000^{\circ} \mathrm{C}$ surface temperature, a cosine distribution in elevation angle $\theta$, and a uniform distribution in azimuthal angle $\oplus$. For each case studied, $1000 \mathrm{CH}_{4}^{\circ}$ molecules are launched. (A chemical sputtering coefficient is thus not explicitly needed or used in this analysis - all results are essentially normalized to an initial sputlering of 1000 particles.'

The collisional processes used in the code, from Ref. [8], are as follows: 
Electron Impact Collision Processes:

$$
\begin{aligned}
& e+\mathrm{CH}_{4} \rightarrow \mathrm{CH}_{4}^{+}+2 e \\
& \mathrm{e}+\mathrm{CH}_{3}+\mathrm{CH}_{3}^{+}+2 \mathrm{e} \\
& \mathrm{e}+\mathrm{CH}_{2} \rightarrow \mathrm{CH}_{2}^{+}+2 \mathrm{e} \\
& \mathrm{e}+\mathrm{CH} \rightarrow \mathrm{CH}^{+}+2 \mathrm{e}
\end{aligned}
$$

$$
\mathrm{e}+\mathrm{CH}_{4} \rightarrow \mathrm{CH}_{3}^{+}+\mathrm{H}+2 \mathrm{e}
$$

$$
\mathrm{e}+\mathrm{CH}_{4} \rightarrow \mathrm{CH}_{2}^{+}+2 \mathrm{H}+2 \mathrm{e}
$$

$$
\mathrm{e}+\mathrm{CH}_{4}+\mathrm{CH}^{+}+3 \mathrm{H}+2 \mathrm{e}
$$

$$
e+\mathrm{CH}_{3}+\mathrm{CH}_{2}^{+}+\mathrm{H}+2 \mathrm{e}
$$

$$
\mathrm{e}+\mathrm{CH}_{2}+\mathrm{CH}^{+}+\mathrm{H}+2 \mathrm{e}
$$

$$
\mathrm{e}+\mathrm{CH}+\mathrm{C}^{+}+\mathrm{H}+2 \mathrm{e}
$$

$$
\mathrm{e}+\mathrm{CH}+\mathrm{C}+\mathrm{H}^{+}+2 \mathrm{e}
$$

$$
e+\mathrm{CH}_{4} \rightarrow \mathrm{CH}_{3}+\mathrm{H}+\mathrm{e}
$$

$$
e+\mathrm{CH}_{3}+\mathrm{CH}_{2}+\mathrm{H}+\mathrm{e}
$$$$
\mathrm{e}+\mathrm{CH}_{2}+\mathrm{CH}+\mathrm{H}+\mathrm{e}
$$$$
\mathrm{e}+\mathrm{CH}+\mathrm{C}+\mathrm{H}+\mathrm{e}
$$

$$
\begin{aligned}
& \mathrm{e}+\mathrm{CH}_{4}^{+}+\mathrm{CH}_{3}+\mathrm{H}^{+}+\mathrm{e} \\
& \mathrm{e}+\mathrm{CH}_{4}^{+}+\mathrm{CH}_{3}^{+}+\mathrm{H}+\mathrm{e}
\end{aligned}
$$




$$
\begin{aligned}
& \mathrm{e}+\mathrm{CH}_{3}^{+}+\mathrm{CH}_{2}+\mathrm{H}^{+}+\mathrm{e} \\
& \mathrm{e}+\mathrm{CH}_{3}^{+}+\mathrm{CH}_{2}^{+}+\mathrm{H}+\mathrm{e} \\
& \mathrm{e}+\mathrm{CH}_{2}^{+} \rightarrow \mathrm{CH}+\mathrm{H}^{+}+\mathrm{e} \\
& \mathrm{e}+\mathrm{CH}_{2}^{+}+\mathrm{CH}^{+}+\mathrm{H}+\mathrm{e} \\
& \mathrm{e}+\mathrm{CH}^{+} \rightarrow \mathrm{C}+\mathrm{H}^{+}+\mathrm{e} \\
& \mathrm{e}+\mathrm{CH}_{4}^{+} \rightarrow \mathrm{H}+\mathrm{C} \\
& \mathrm{e}+\mathrm{CH}_{3}^{+}+\mathrm{H} \\
& \mathrm{e}+\mathrm{CH}_{2}^{+} 2 \mathrm{H} \\
& \mathrm{e}+\mathrm{CH}_{3}^{+} \rightarrow \mathrm{CH}_{2}^{+} \rightarrow \mathrm{H} \\
& \mathrm{e}+\mathrm{CH}^{+} \rightarrow \mathrm{C}+\mathrm{H} \\
& +\mathrm{CH}^{+}+\mathrm{CH}^{+} \mathrm{H}
\end{aligned}
$$

Hydrogen Ion Impact Collision Reactions:

$$
\begin{aligned}
& \mathrm{H}^{+}+\mathrm{CH}_{4}+\mathrm{CH}_{4}^{+}+\mathrm{H} \\
& \mathrm{H}^{+}+\mathrm{CH}_{3}+\mathrm{CH}_{3}^{+}+\mathrm{H} \\
& \mathrm{H}^{+}+\mathrm{CH}_{2}+\mathrm{CH}_{2}^{+}+\mathrm{H} \\
& \mathrm{H}^{+}+\mathrm{CH}+\mathrm{CH}^{+}+\mathrm{H} \\
& \mathrm{H}^{+}+\mathrm{C} \rightarrow \mathrm{C}^{+}+\mathrm{H}
\end{aligned}
$$


The code also includes electron impact ionization reactions for carbon ions. The above reactions are implemented using the Monte Carlo technique for simulating charge changing collisions described in Ref. [1]. A hydrogen mass of 2.5 AMU was used for all calculations. Momentum transfer, based on the Ref. [8] reaction energetics estimates, is included where appropriate.

A particle (carbon or hydrocarton) history terminates upon reaching the surface, i.e. being redeposited, or upon leaving the near-surface region $(z)$ $1 \mathrm{~cm})$. Parameters of the redeposited particles are computed including the physical sputtering coefficient and a chemical sputtering amplification factor, $r$, due to reflection. The reflection model is described in the appendix.

\section{RESULTS}

Cases were run for a reference plasma with magnetic field $B=5 T$, field angle $\Psi=87^{\circ}$, sheath potential $e \phi_{O}=-3 \mathrm{kT}_{e}$, and sheath parameter (see Ref. [1]) $f_{D}=0.25$. These parameters are typical of the conditions expected near a tokamak reactor divertor plate. An electron density (prior to the sheath) of $\mathrm{N}_{\mathrm{e}_{0}}=3 \times 10^{20} \mathrm{~m}^{-3}$ was used, for the reference cases. Cases were run for plasma temperatures $\mathrm{T}_{e}=\mathrm{T}_{\mathrm{i}}$ in the range of $1-200 \mathrm{eV}$. The lower temperature cases are potentially significant for regions at some distance from the divertor strike point where there is still appreciable particle flux, e.g. as shown in calculations(10) for the ITER device, and where hydrogen ion impingement energies $\left(\sim 5 \mathrm{~T}_{\mathrm{e}}\right)$ appear to be high enough for significant chemical sputtering (11).

As an example of the particle trajectories computed, Fig 2. shows five selected histories for the case of $\mathrm{T}_{e}=10 \mathrm{eV}$. For simplicity, the trajectories are shown only in two dimensions. As stated, all particles are launched as neutral methane. Each dot in Fig. 2 represents a subsequent atomic or molecular collision. As shown, the transport process is fairly complex. Of the five trajectories shown in Fig. 2, four result in redeposition in the form of hydrocarbons, and one results in redeposition of a carbon ion. The latter event is not shown because distances involved are outside the scale of the figure. 


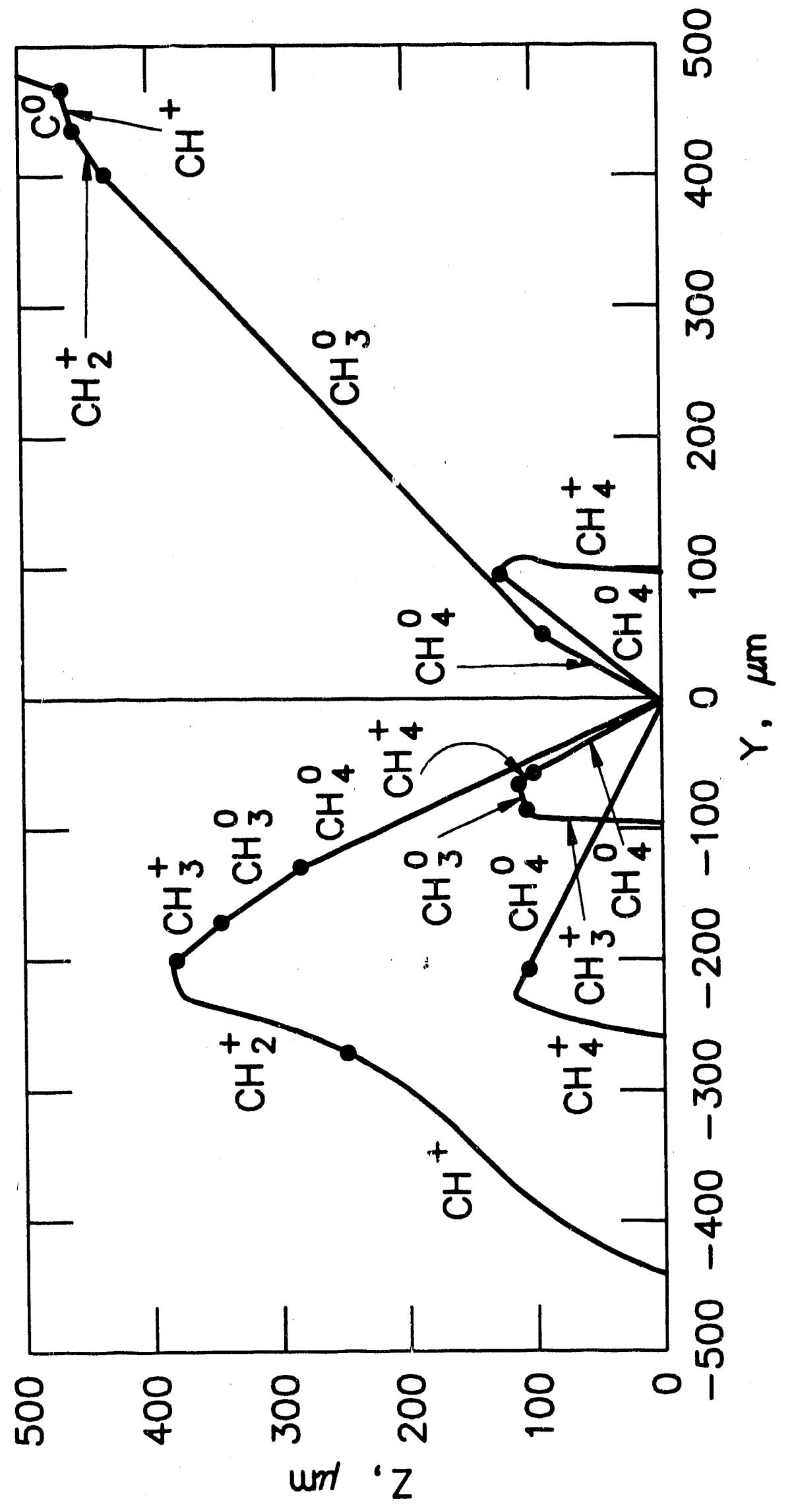

ट 
Tablle 1 summarizes the redeposited particle parameters and Elig. 3i shows the redepositted species mix for the reference pilasma cases. Al key difference in chemical sputtering vs. physicall sputtering is that the mean free paths for ionization of the sputtered $\mathrm{CH}_{4}{ }^{\circ}$ and distances for the entire transport. process: are albout a factor of ten less than those for physicalliy sputtered carbon. This is due to the lower sputtered energy, hilgher mass, and hilgher ionization cross sections for $\mathrm{CH}_{4}$ a compared with $\mathrm{C}^{\circ}$. In generall, the chemically sputtered carbon meam free path is laarge compared to the Debye sheath widith $\left(e . g .6 x_{D}=8 \mu \mathrm{m}\right.$ at $\left.T_{e}=10 \mathrm{ev}\right)$, comparabile to the magnetic sheath widith (e.g. $-3 R_{D T} \approx 300 \mu m$ at $T_{e}=10$ eV'), and very small compared to typilical scrape off layer pllasma temperature gradient scale widths: ( severall $\mathrm{cm}$ ).

At plasma temperatures $T_{e} \geq 10$ eV essentialliy all chemically sputtered cartion is redeposited. At lower plasma temperatures redeposition drops off substantially. This is primarily due to the fall of $f$ of electron impact ionization rates for $\mathrm{T}_{e}<10 \mathrm{eV}$. The species mix and neutral fractions of redeposited carbon are also substantially different at $\mathrm{T}_{e}<10 \mathrm{ev}$, because of significant variations in rate coefficients. It should be noted that the redeposition fraction referred to in this work refers only to carbon that is redeposited by immediate ionization and transport in the near-surface region. In a tokamak, sputtered material may also be redeposited after transport in the plasma edge or core region and subsequent return of material to the divertor.

As shown in Table 1, the average redeposited energy and the average physical sputtering coefficient for the redeposited particles are fairly low. Except for the highest temperature case, $\mathrm{T}_{e}=200 \mathrm{eV}$, physical sputtering of carbon by redeposited, chemically sputtered carbon, is insignificant. Hydrocarbon reflection, however, is high over most of the plasma regime studied. Note that a value of $\gamma=4$, for example, implies that a total of 4 methane molecules would be emitted for every hydrogen chemical sputtering event. Depending on the chemical sputtering coefficient, it is thus possible for a high carbon impurity content to arise in the near-surface plasma.

The effect of plasma density on the carbon transport was examined. Table 2 summarizes results for a broad range of densities. The case of $\mathrm{N}_{e_{0}}=3 \mathrm{x}$ $10^{20} \mathrm{~m}^{-3}$ is repeated, for comparison. The value of $N_{e_{0}}=10^{21} \mathrm{~m}^{-3}$ may also be 


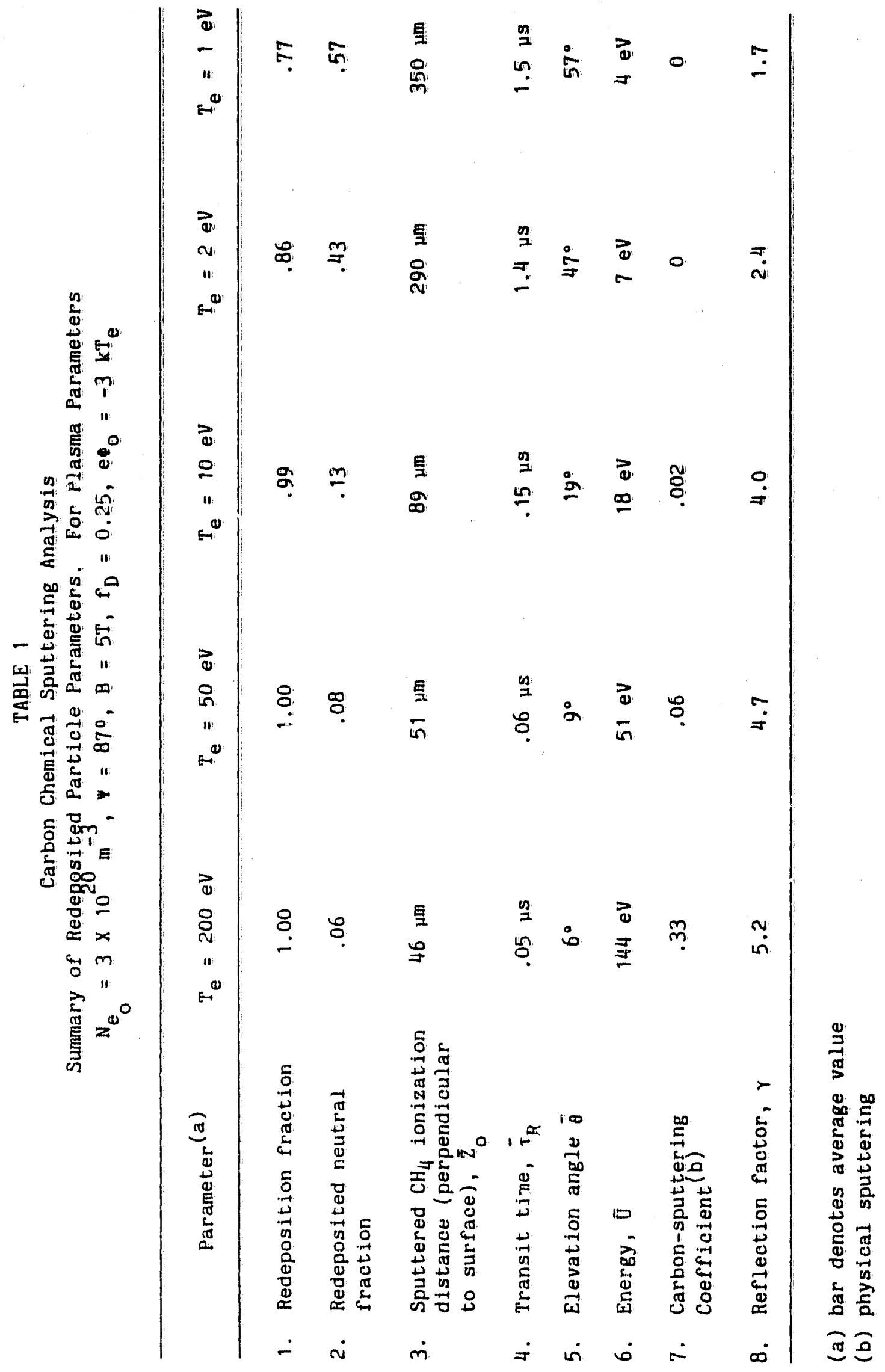




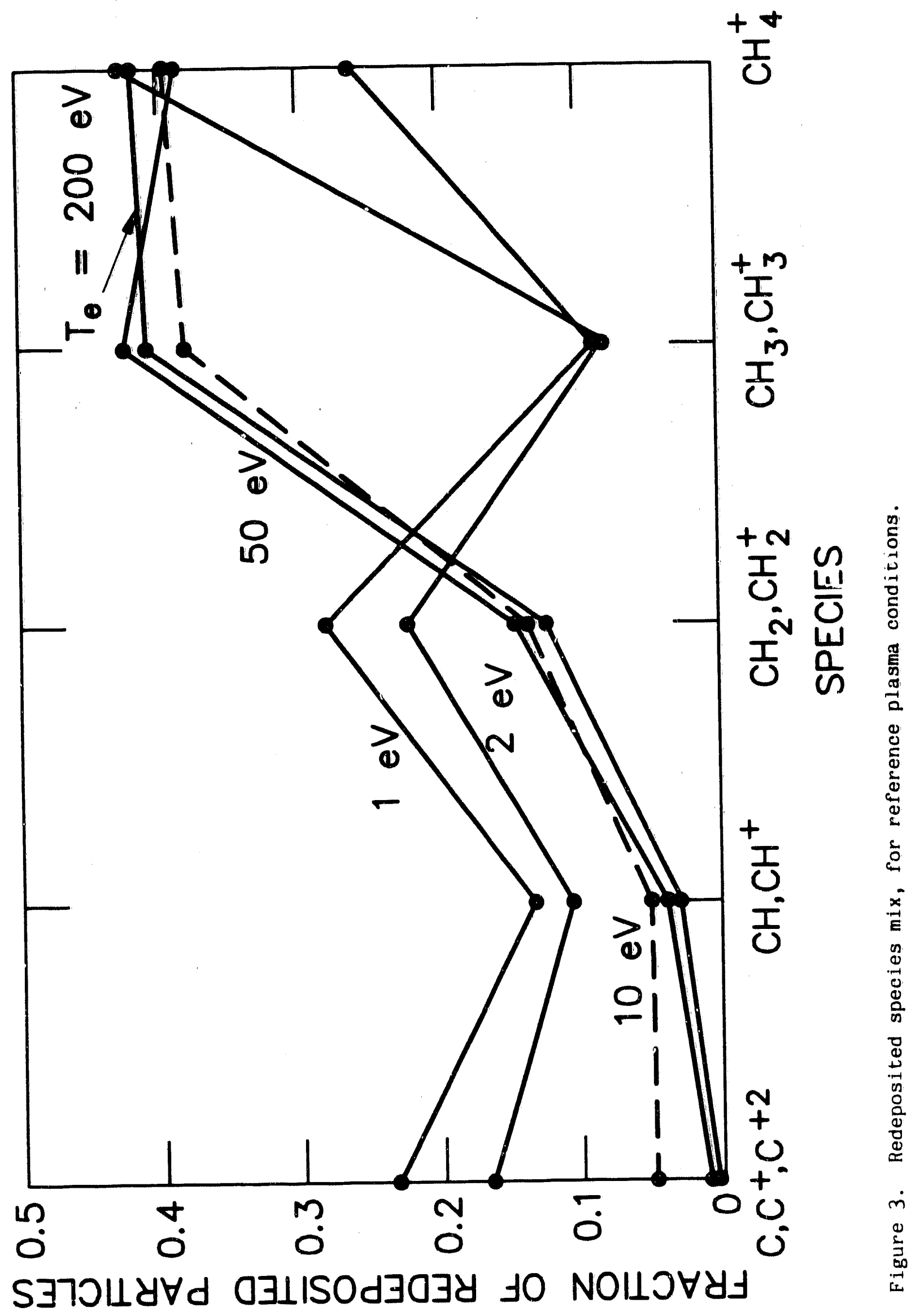




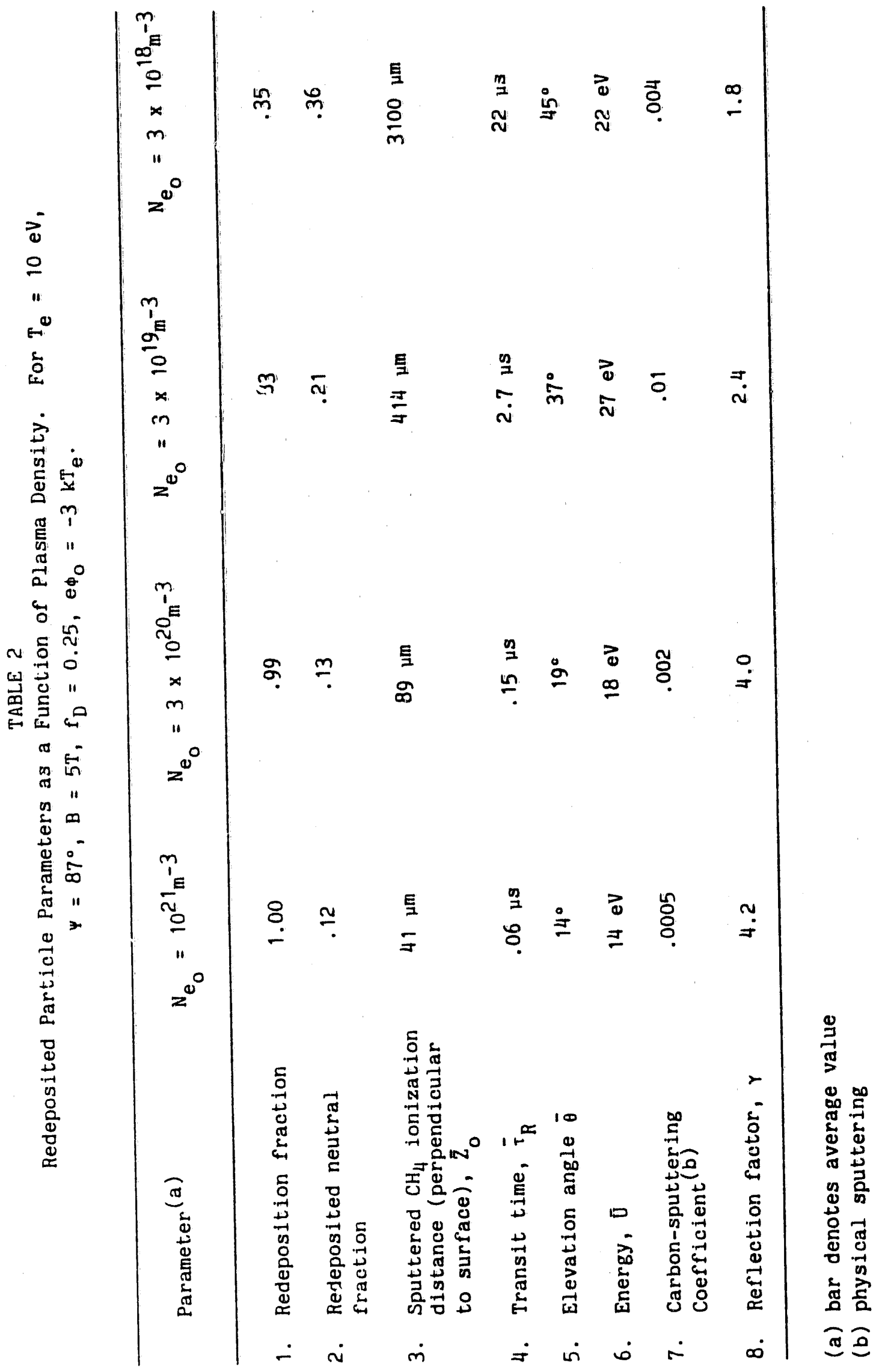


obtained for high recycling divertor conditiuns. The lower values of density are not expected for divertor conditions but may be characteristic of certain limiter regimes or non-tokamak plasmas, e.g. plasma assisted vapor deposition apparatus. A significant variation with density is predicted in the redeposition fraction which declines at lower densities. This is primarily due to the increase in ionization mean free paths with decreasing density.

\section{CONCLUSIONS}

This study has examined the transport of chemically sputtered carbon at a divertor plate. The analysis considers the carbon and hydrocarbon motion in detail, as well as the applicable atomic and molecular reactions. A trace impurity content, oblique magnetic field sheath model is used for the analysis. A key uncertainty is the properties of the redeposited carbon surface and particularly the reflection properties of impinging hydrocarbons. The reflection model used is believed reasonable regarding overall trends but experimental data regardinfs reicposited carbon surface properties is required to develop a predictive computaticnal capability.

The calculations show that most of the ionization and subsequent transport of chemically sputtered carbon particles occurs very close to the surface, for typical divertor conditions. For plasma temperatures of $10 \mathrm{eV}$ and greater, redeposited particles tend to impinge at near normal incidence, and with energies ranging from about one third to one half of the sheath potential. Redeposition parameters appear to be substantially different for very low temperature regimes, due to sharp differences in the collisional rate coefficients.

The high redeposition fractions predicted for plasma regimes of $\mathrm{T}_{e} \geq 10$ $\mathrm{eV}$ and $\mathrm{N}_{\mathrm{e}_{0}} \geq 3 \times 10^{20} \mathrm{~m}^{-3}$ imply little or no net erosion of carbon due to chemical sputtering. This is encouraging for the use of carbon as a surface material. The high potential hydrocarbon reflection, however, gives rise to concerns about deleterious effects of high concentrations of carbon impurity ions on the local plasma. Studies of non-trace impurity effects on the sheath and local plasma are planned to examine this issue. The effect of oxygen chemical sputtering of carbon is also an important issue needing analysis. 


\section{REFERENCES}

1. J.N. Brooks, Phys. Fluids B 2 (1990) 1858.

2. J.N. Brooks and D.N. Ruzic, J. Nuc. Mat. $176 \& 177$ (1990) 278.

3. J.N. Brooks, H.F. Dylla, A. Pontau, and K. Wilson, Fus. Tech. 19 (1991) 1095 .

4. J.N. Brooks, Argonne Nat1. Lab. Report ANL/FPP/TM-255, 1991.

5. P.C. Stangeby and G.M. McCracken, Nuc. Fus. 30 (1990) 1225.

6. W.D. Langer, Nuc. Fus. 22 (1982) 751.

7. J.N. Brooks Fus. Tech. $18(1990) 239$.

8. A.B. Ehrhardt and W.D. Langer, Princeton Plasma Physics Laboratory Report PPPL-2477, 1987.

9. D. Ruzic, University of Illinois, Pers. Comm. (1991).

10. S. Cohen, K.A. Werley, D.E. Post, B.J Braams, J.L. Perkins, and D. Pearlstein, J. Nuc. Mat. 176 \& 177 (1990) 909.

11. J. Roth, E. Vietzke, and A.A. Haasz, Nuc. Fus. Supplement 1 (1991) 63. 


\section{APPENDIX}

\section{Hydrocarbon Reflection Model}

This model was developed $(9)$ to provide a rough estimate of the carbon emission cascade resulting from chemical sputtering and subsequent redeposition. The model is based on the consideration that in order to stick to the surface, an impinging hydrocarbon has to lose its hydrogen. The bond breaking mecharisms in the surface are strongest for $\mathrm{CH}$ and weakest for $\mathrm{CH}_{4}$. A redeposited carbon ion or atom therefore sticks most readily and $\mathrm{CH}_{4}$ least readily. Particles that do not stick are assumed to be re-emitted as $\mathrm{CH}_{4}$ with the same velocity distribution as chemically sputtered methane. The above considerations lead to the following ad-hoc values for reflection coefficients.

INCIDENT SPECIES

(ion or atom)
REFLECTION COEFFICIENTS

(for emission as $\mathrm{CH}_{4}$ )

$\begin{array}{ll}\mathrm{C} & 0 \\ \mathrm{CH} & .25 \\ \mathrm{CH}_{2} & .50 \\ \mathrm{CH}_{3} & .75 \\ \mathrm{CH}_{4} & 1.0\end{array}$

Using these reflection coefficients together with the redeposited species fractions computed by the WBC code, a chemical sputtering flux amplification factor due to reflection can be computed as follows:

$$
r=\frac{\text { methane emitted due to sputtering + reflection }}{\text { methane emitted due to sputtering alone }}
$$

For no reflection, therefore, $\gamma=1$, and for unity reflection, $\gamma=\infty$. 


\section{DISTRIBUTION LIST FOR ANL/FPP/TM-259}

Internal
H. Attaya
T. Hua
B. Picologlou
M. Billone
A. Hul1
C. Reed
J. Brooks (10)
C. Johnson
D. Smith
D. Ehst
A. Krauss
D. Sze
P. Finn
L. LeSage
FPP Files (15)
Y. Gohar
B. Loomis
ANL Contract File
D. Gruen
S. Majumdar
ANL Patent Dept
A. Hassane in
R. Mattas
TIS Files ( 3 )

\section{External}

DOE-OSTI, for distribution per UC-421 and UC-423 (49)

Manager, Chicago Operation Office

ANL-TIS Libraries

C. Baker, Oak Ridge National Laboratory

R. Causey, Sandia National Laboratories, Livermore

H. Chiu, General Atomics

M. Cohen, Office of Fusion Energy, DOE

S. Cohen, Princeton Plasma Physics Laboratory

K. Dimmof, Institute National de la Recherche Scientifique

A. Haasz, University of Toronto

M. Harrison, Culham Laboratory

Y. Hirooka, University of California, Los Angeles

W. Hsu, Sandia National Laboratories, Livermore

D. Manos, Princeton Plasma Physics Laboratory

P. Mioduszewski, Oak Ridge National Laboratory

R. McGrath, Sandia National Laboratories, Albuquerque

R. Nygren, Sandia National Laboratories, Albuquerque

K. Parbhakar, Institut National de la Recherche Scientifique

D. Ruzic, University of Illinois, Urbana

P. Stangeby, University of Toronto

M. Ulrickson, Princeton Plasma Physics Laboratory

$J$. Wesley, General Atomics

K. Wilson, Sandia National Laboratories, Livermore

J. Winter, KFA Julich, Germany

C. Wong, General Atomics

C. Wu Max-Planck Institute fur Plasmaphysik, Germany

Bibliothek, Max-Planck Institute fur Plasmaphysik, Germany

Bibliothek, Institute fur Plasmaphysik, KFA Julich, Germany

C.E.A. Library, Fontenay-aux-Roses, France

Librarian, Culham Laboratory, England

Library, Commission of the European Community, Italy

Thermonuclear Library, Japan Atomic Energy Research Institute, Japan 

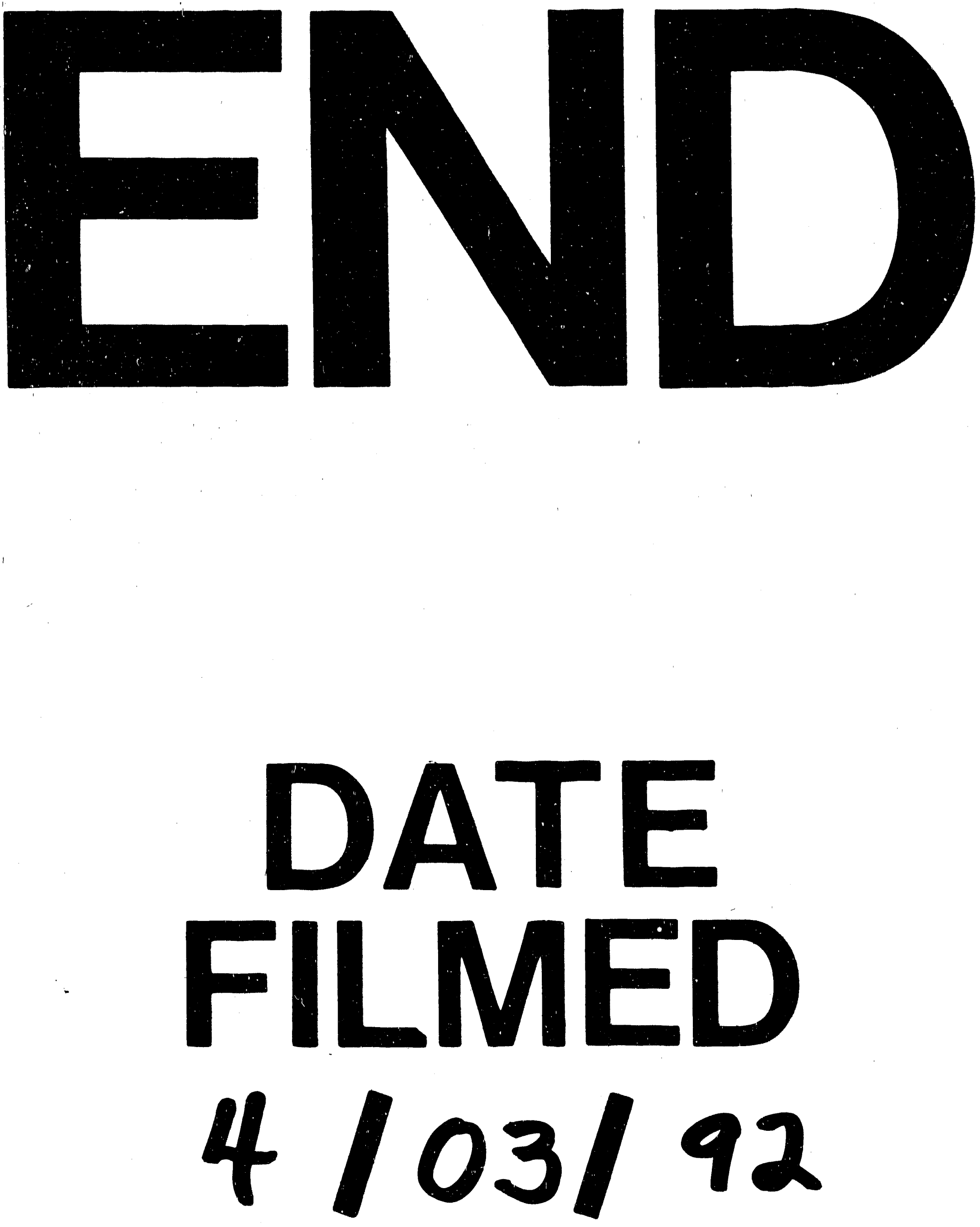

92 
